\title{
Conference on Higher Education in Southeast Asia Centre for Khmer Studies in Siem Reap, January 2008
}

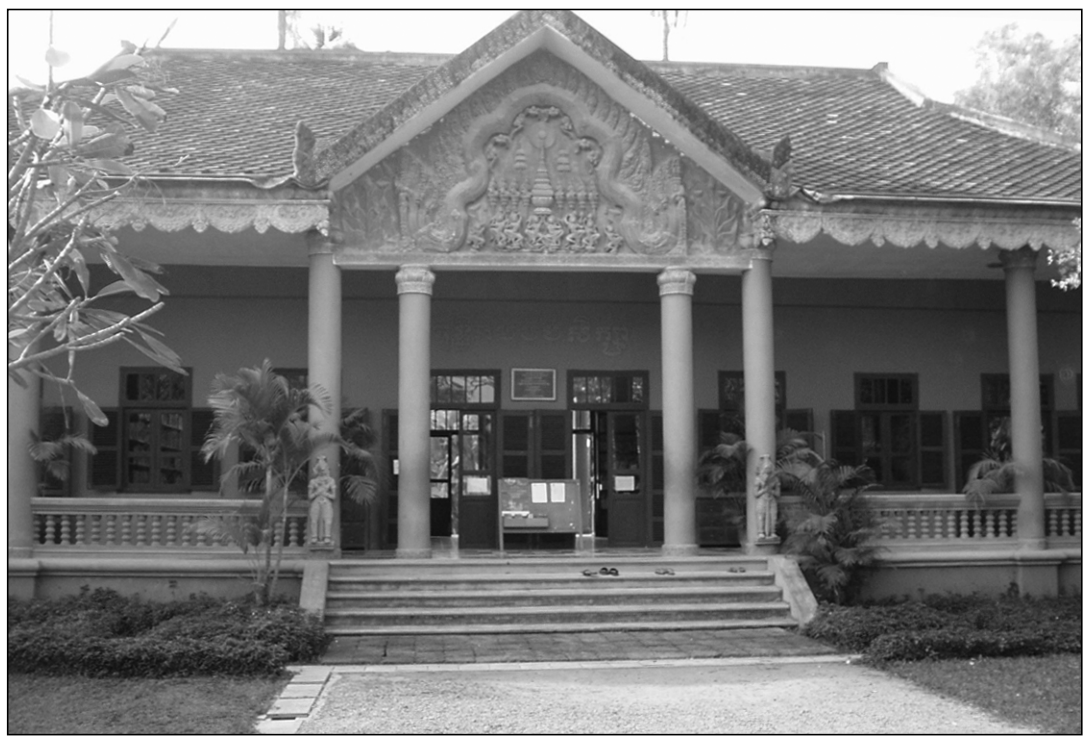

Conference Site. Library of the Centre for Kbmer Studies.

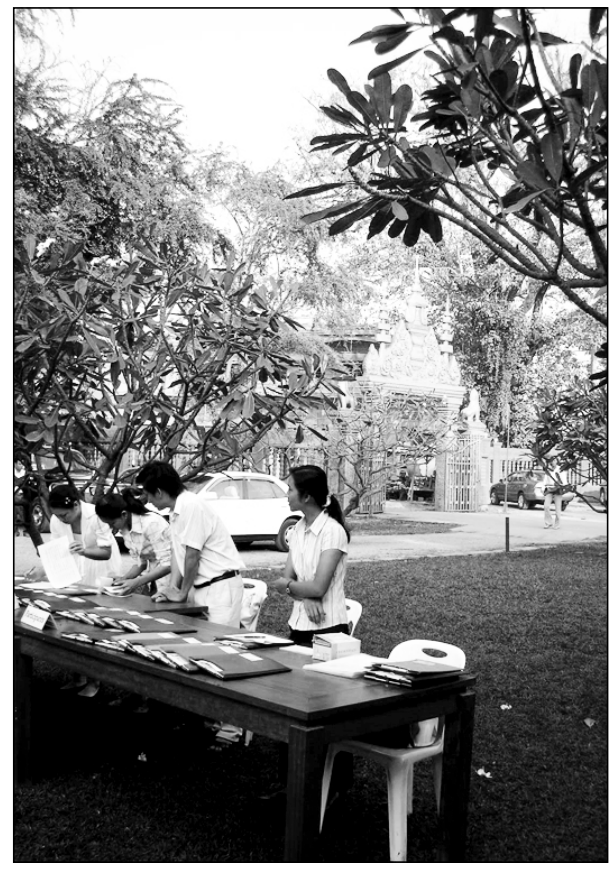

Conference

Registration

January 2008

Education canadienne et internationale Vol. $39 n^{0} 1$ - avril 2010 


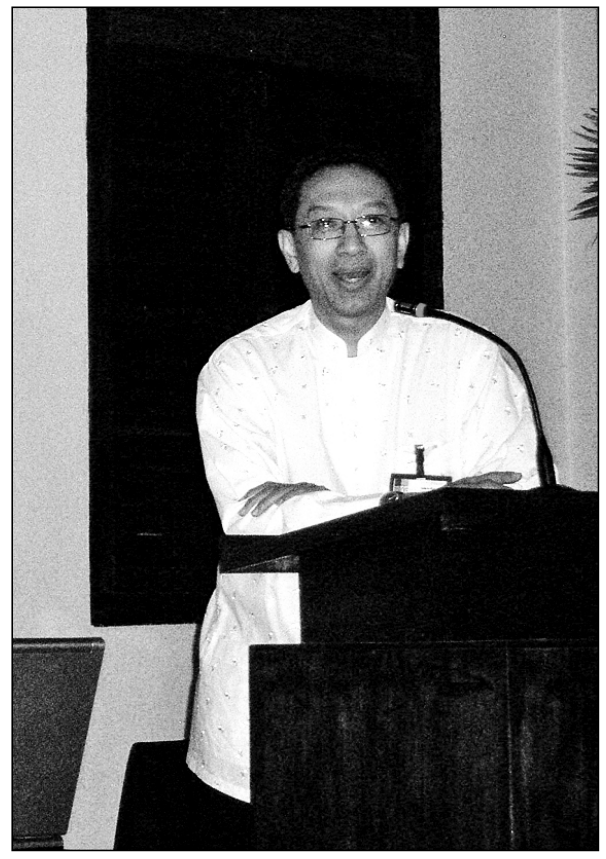

Professor Rethy Chbem addressing the conference (apparently in SE Asia, Professor is more prestigious than Dr.)

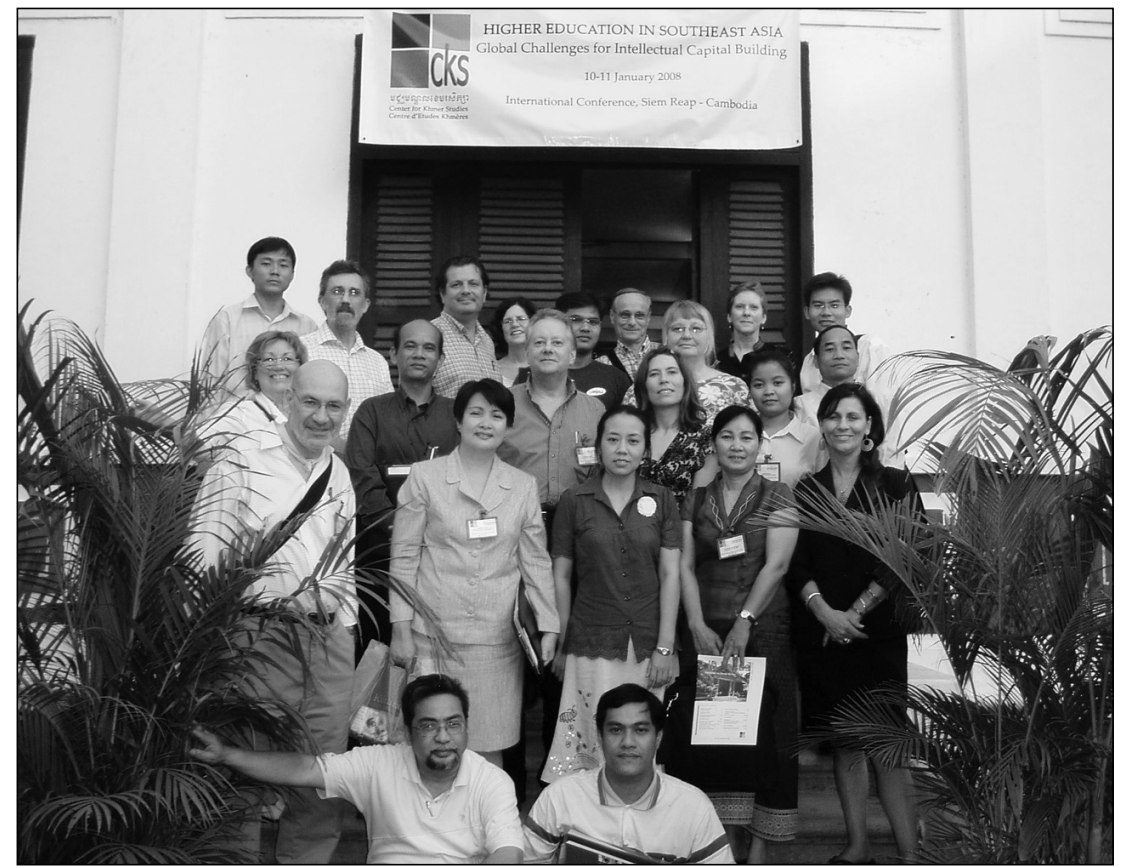

Some conference participants at the Centre for Kbmer Studies.

68 Canadian and International Education Vol. 39 no. 1 -April 2010 


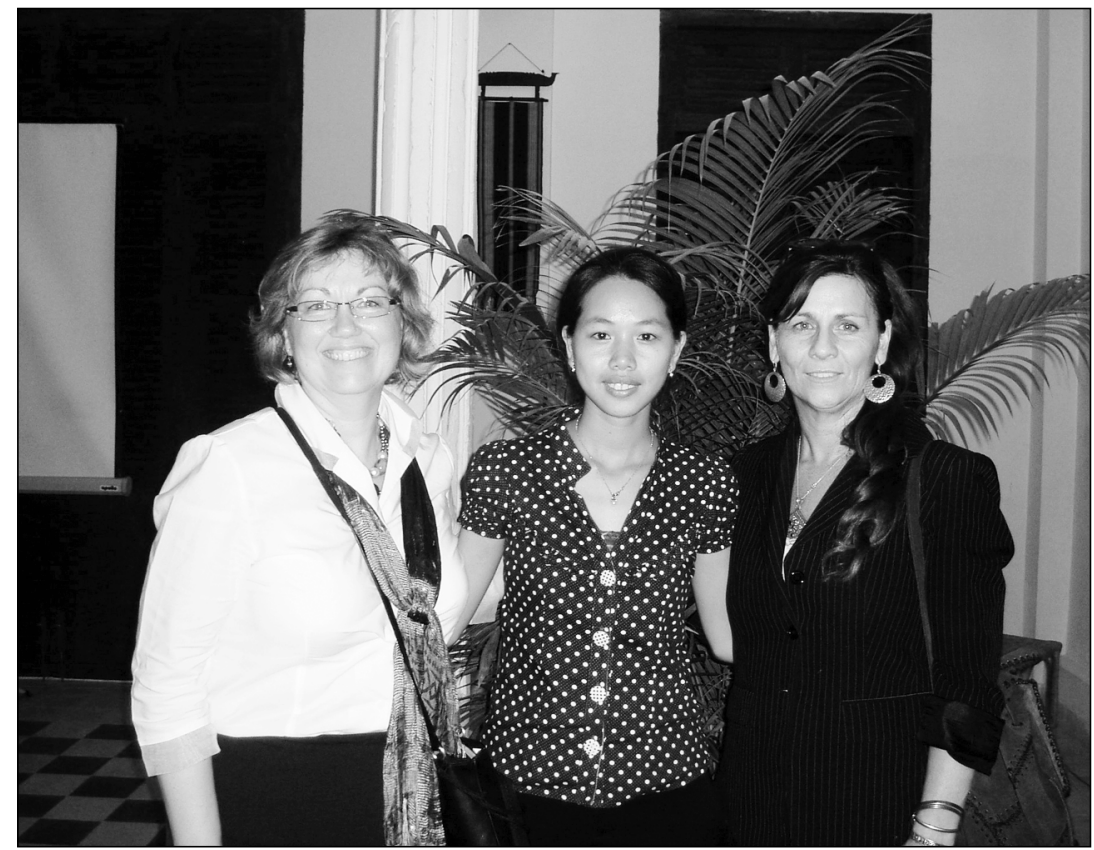

Kathy Hibbert, Titb Srey Pich and Teresa Van Deven

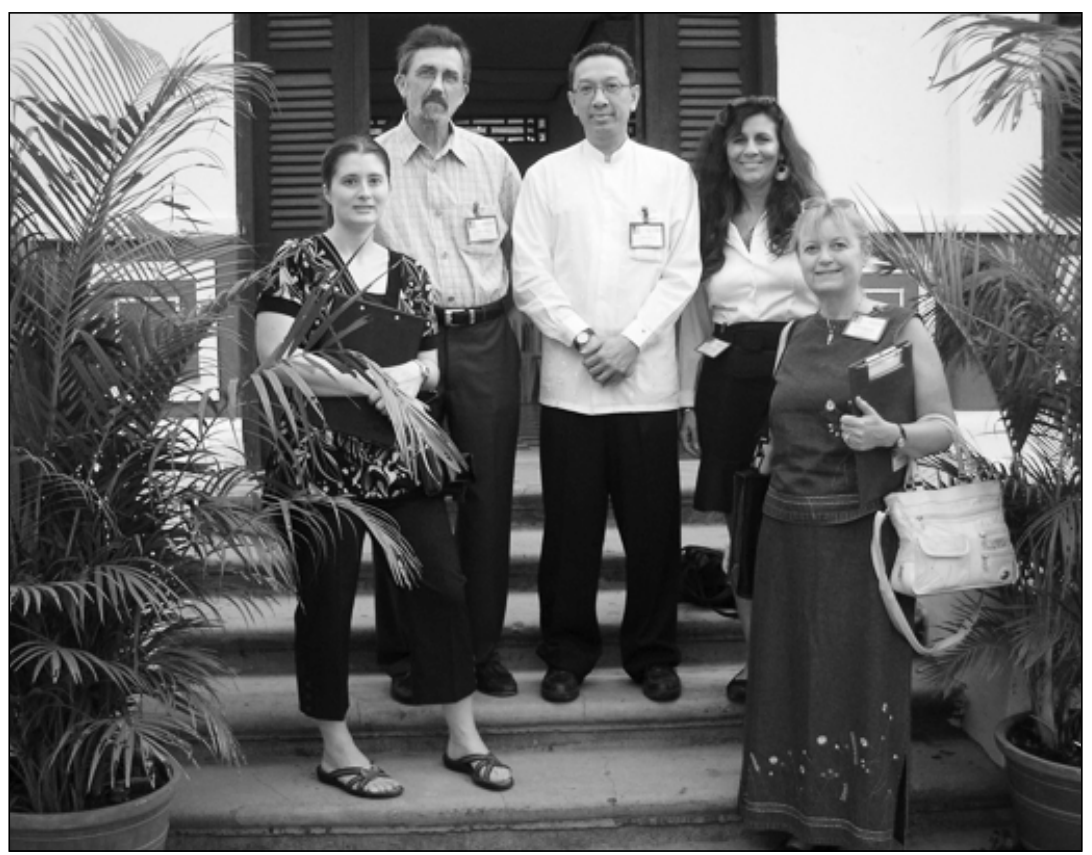

Some of the Canadian participants with Professor Rethy Chbem in front of the Centre for Khmer Studies

Education canadienne et internationale Vol. 39 n 1 - avril 2010 